\title{
Unsaturated Iron Binding Capacity Measurement
}

National Cancer Institute

\section{Source}

National Cancer Institute. Unsaturated Iron Binding Capacity Measurement. NCI

Thesaurus. Code C74719.

The determination of the binding capacity of unsaturated iron in a sample. 